\title{
BIA, DPA, MBTA and DMA as Vapour Phase Corrosion Inhibitors for Mild Steel under different Atmospheric Conditions
}

\author{
Harish Kumar *, Vikas Yadav \\ Material Science \& Electrochemistry Laboratory, Department of Chemistry, \\ Chaudhary Devi Lal University, Sirsa, Haryana - 125055 , India \\ ${ }^{*}$ Ph. 094660 77870, Fax (91) 01666-248123 \\ *E-mail address: harimoudgil1@rediffmail.com
}

ABSTRACT

Mild steel is widely used as main raw material in fabric on o uipment, chief material of construction and as weapons. During its storage and transp on con it comes in contact with aggressive environment which leads to decrease mechanical stro ith and loss in useful properties. Four different vapor phase corrosion inhi tors (VPCIs) i.e. Benzaimidazole (BIA), Diphenyl amine (DPA), 2-mercapto benzothiazole (ME A) and N,N-limethyl aniline (DMA) were tested under different atmospheric conditions at $40{ }^{\circ} \mathrm{C}$ b. Veight Lo $s$, Eschke test, Salt Spray, $\mathrm{SO}_{2}$ test and SEM techniques. All the four VPCIs s $\mathrm{s}^{\text {haw }}$ good co mibition efficiency i.e. $65-96 \%$. The results obtained from all the four corrosion in ants were supported by SEM images.

Keywords: Mild steel; Atmospheric corrosion; Va phase corrosion inhibitors; Eschke Test

\section{INTRODUCTION}

Mild steel is mos ammon form of steel and because of its low cost it is chief material of con ruction. Mild $Y$ have good strength, hard and can be bent, worked or can be welded in an e less varicty of shapes for uses from vehicles (like cars and ships) to building matc Becaus of its unique properties like, very cheap, high strength, hardness and eas yailas it as wide range of applications in nut bolt, chains, hinges, knives, arm ar, $p_{\text {s }}$ s, magh military equipments etc.

tm anheric orrosion also known as vapor phase corrosion (VPC) is due to the indivi anu combined action of oxygen, moisture, and atmospheric pollutants. Additional contribu. to VPC are rain, snow, dust, soot, ash, wind, and radiation (light, heat, etc.). The rate of VPY may be accelerated by both acids and bases, depending upon the metal.

Metal and their alloys are exposed to aggressive environment under atmospheric condition during the manufacture, processing, storage, or transportation and can accelerate the degradation of the metal, alloys and their products. In such cases, the corrosion prevention methods like water-displacing products (oil or grease), water-absorption products (silica gel) and dehumidification are not significant due to high labor, material cost for the application and removal of product and difficulty to calculate specific moisture. The vapor phase corrosion inhibitors (VPCI) play a significant role in minimizing corrosion to metals 
and their alloy in atmospheric condition by producing vapors with sufficient vapor pressure due to their volatile nature, and prevent the metal or alloys from corrosion by adsorption of their vapors onto the metal surface. The effective use of surfactants for VPCI depends upon environment and properties of metals as well as surfactants [1-5]. It has been shown for iron that when relative humidity is below 60 percent, no corrosion is expected, while above 75 to 80 percent, the degree of corrosion will be high [6]. Detrimental effects caused by photochemical reactions of sulphur dioxide and nitrogen oxides have been demonstrated by Stern [7].

Use of VPCI is an effective method to prevent atmospheric corrosion [8 0] The corrosion inhibitors volatizes into the atmosphere surrounding the metal and thy modis, atmosphere [10]. The choice of a chemical compound as VPCIs depends up on its vap pressure and efficiency to prevent corrosion by forming a protective film. The $v_{\text {a }}$ pressu of VPCI must posses some optimum values. If the vapor pressure of the PCI is to $\mathrm{v}, \mathrm{g}$. in the order of $10^{-6}$ Torr at room temperature, the protective vape conce gation 11 be established only slowly. This may result in insufficient corrosion roto during initial time period. Further, if the space that houses both the stored equipmen nd $\mathrm{Y}_{\mathrm{P}} \mathrm{CI}$ is not sealed, sufficient inhibitor concentration may not be reac $a$ Conversely ander similar conditions, if the vapor pressure of VPCI is too high (appro 0.1 at amblent conditions), its effectiveness will be limited to a short time period, pits onsump ate will be high.

Subramanian et. al [11] studied the most commonly used VPCI, derivatives of ammonium carbonate and ammoniumnitrite on cop $r$, mild steel and zinc in sulphur dioxide $\left(\mathrm{SO}_{2}\right)$ environments. Due to their easily availabili and their better percentage corrosion inhibition efficiency (PCIE) they have been used in hy or several decades. However, the disadvantages of using these derivative an toxic nature to the environment. Thus, replacing them with new environmental frie dly atm. ors is desirable. Saurbier et. al [12] suggested toluylalanine as an effertive tem orary mhibitor of steel in wet atmosphere. Vuorinew [13] reported a ser es o morpho ine-mannich based derivatives as volatile corrosion inhibitors. Polyme corr sion inh oitors such as polyacrylic and polyamnobenzoquinone etc. are wi a $\mathrm{y}$ have a lower toxicity than their monomers $[14,15]$. Many kinds of orpholine vomer (MPO) as VPI for the temporary protection of box shaped hatch co ers d rudder ades of large ships at Hudong Shipyard have been studied by Zhang 2 al. [1 Quraishi et al. [17] studied the inhibiting properties of five organic vapor nase inhibitors mely, derivatives of imidazoline maleate, orthophosphate, nitrobenzoat phtha cinnanate on mild steel, brass and copper. They also studied some organic vola corrosi inhibitors mostly derivative of diaminohexane such as diamin ane nitrobenzoate, phthalate, orthophosphate and maleate on alur iniun zinc an mild steel [18]. Study of some salts of benzoic hydrazide benzoate (Bh b 2 hudrazide salicylate (BHS) and benzoic hydrazide nitrobenzoate (BHN) as corros inhibitors of mild steel [19-21], brass and copper was studied by weight loss method [2 Quraishi, 2005). Persiantsava, examined derivatives of benzene with $\beta$-napthol as a VPCI $n$ a sulphur dioxide and chloride atmosphere [23]. Subrumanian et al., studied the corrosion inhibition behaviour of morpholine and its three derivatives salts- morpholine carbonate, borates, and phosphates salts [24]. Of these morpholine and its carbonates salt exhibited 90 and $85 \%$ corrosion inhibition efficiency (CIE) respectively while the other salts gave less than $40 \%$ corrosion inhibition efficiency.

In continuation to our earlier study [25-29], in the present study, the inhibiting properties of four organic VPCIs named as Benzaimidazole (BIA), Diphenyl amine (DPA), 2-mercapto benzothiazole (MBTA) and N,N-dimethyl aniline (DMA) were investigated on 
mild steel by Weight Loss technique at $85 \%$ of relative humidity and $40{ }^{\circ} \mathrm{C}$ temperature, Salt Spray method in a medium of $3.0 \%$ sodium chloride, Eschke test, $\mathrm{SO}_{2}$ test and $\mathrm{SEM}$ techniques.

\section{EXPERIMENTAL}

Name, structure and molecular formula of four VPCI for Mild steel are shown in Table 1. These VPCIs were selected due to their easily availability, suitable vapor pressum-less toxic nature, high durability, and cost effective nature.

Mild steel (ASTM-283) used for the investigation was in the form of $c$ at $(0.025$ thick) and had the following composition: $\mathrm{C}, 0.17$; Si, 0.35; Mn, 0.42; S $0.05,0.20$; 1 $0.01 ; \mathrm{Cu}, 0.01 ; \mathrm{Cr}, 0.01$, and $\mathrm{Fe}$, balance $(\mathrm{w} / \mathrm{w})$.

The mild steel coupons of dimensions $3.0 \mathrm{~cm} \times 1.5 \mathrm{~cm} \times 025 \mathrm{~cm}$ vere $\mathrm{u}$ a for different corrosion tests. Metal specimens were mechanically poli ea essivel with the help of emery papers of grades 100,200,300, 400 and 600 nicron a then noroughly cleaned with plenty of triple distilled water (conductivity lo os $1 \times 10^{-6} \mathrm{~m}^{-1} \mathrm{~cm}^{-1}$ ) and then with acetone. The specimens were dried with hot air low d stored in desiccators over silica gel. Duplicate in some case triplicate exp nmint were formed to check the
reproducibility of data.

Table 1. Name and structure of four Vapo Phase Corr sion Inhibitors.

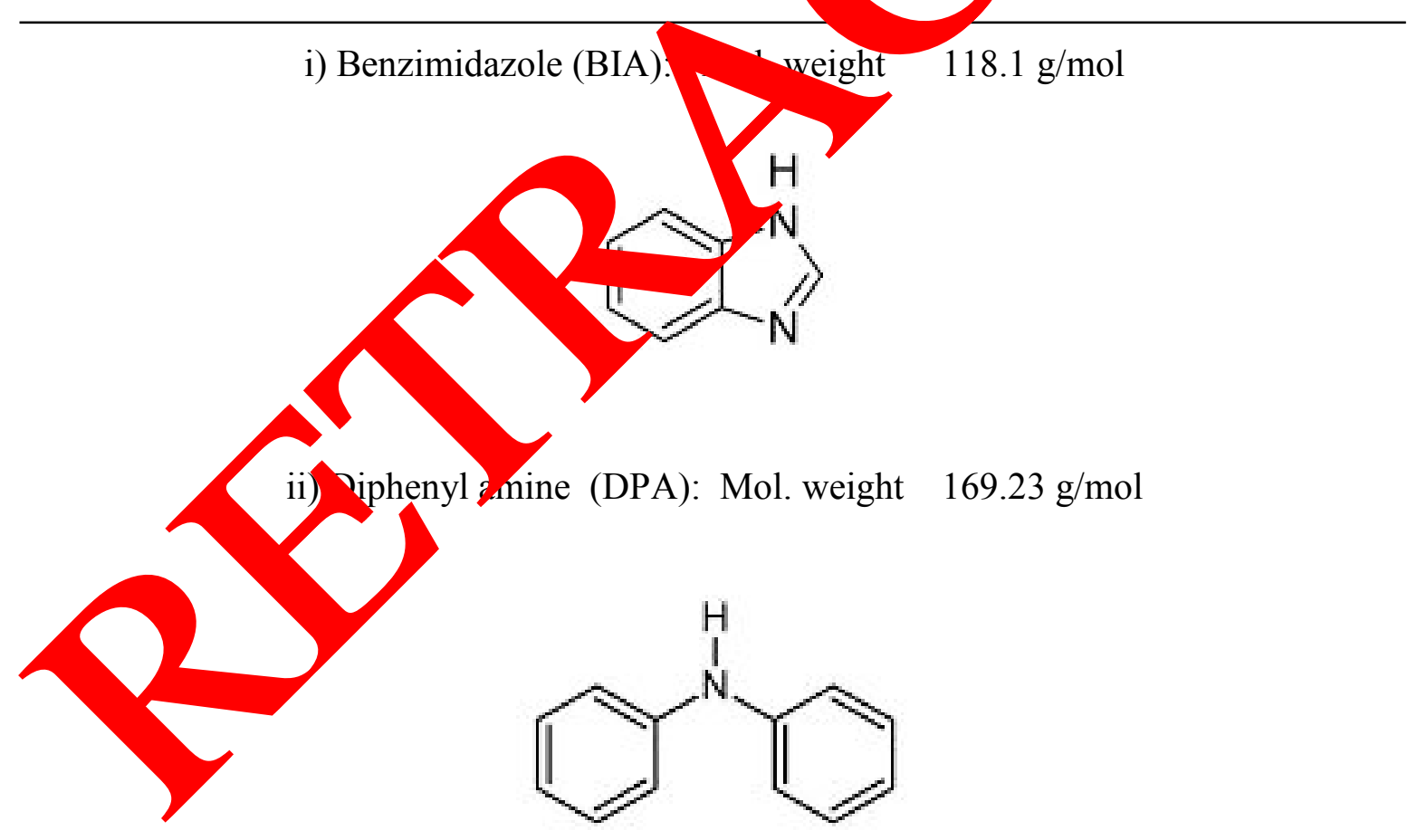

iii) 2-Mercapto Benzothiazole : Mol. weight $167.25 \mathrm{~g} / \mathrm{mol}$ 
<smiles>S=c1[nH]c2ccccc2s1</smiles>

iv) N-N-dimethyl aniline (DMA): Mol Wt. $121.18 \mathrm{~g} / \mathrm{mol}$

\section{1. Vapor Pressure Determination Test}

A standard Knudsen method [30] wa to dewne the vapor pressure of all the four VPCIs. Definite amount of exactly wee hea CIs were placed in a single neck round bottom flask fitted with a rubber cork in the $\mathrm{n}$ navits a glass capillary of $1.0 \mathrm{~mm}$ diameter in the center of rubber cork.

Then the flask was kept air th rmostat aintained at the constant temperature of 40 ${ }^{\circ} \mathrm{C}$ for 10 days. Change in he balance $(0.01 \mathrm{mg}$ accu acy). $\mathrm{h}$. pressure of all the four investigated VPCIs was determined by equatio and has by hown in Table 2 .

Table 2. y a pour pressure the four investigated Vapour Phase Corrosion Inhibitors.

$\begin{array}{ll}\text { Cor sion Inhibitors } & \text { Vapour pressure (mm Hg) } \\ \text { D. } & 1.038 \\ \text { Diphentimidazole } & 1.0229 \\ \text { 2-Mercapto Benzothiazole } & 1.0276 \\ \text { DMA } & 4.608\end{array}$




$$
P=\frac{W}{A t}\left[\frac{2 \pi R T}{M}\right]^{1 / 2}
$$

Where, $P=$ vapor pressure of the VPCI ( $\mathrm{mm}$ of $\mathrm{Hg}), A=$ area of the orifice $\left(\mathrm{m}^{2}\right), t=$ time of exposure (sec.), $W=$ weight loss of substance $(\mathrm{kg}), T=$ temperature $(\mathrm{K}), M=$ molecular mass of the inhibitor $(\mathrm{kg})$ and $R=$ gas constant $\left(8.314 \mathrm{JK}^{-1} \mathrm{~mol}^{-1}\right)$.

\section{2. Weight Loss Technique}

Weight loss experiments were carried out in an electronically controlled ir thermos (perfectly insulated) maintained at a constant temperature of $40{ }^{\circ} \mathrm{C}$ with in a curacy $\pm 0.1^{\circ} \mathrm{C}$. Four vapour phase corrosion inhibitors namely Benzaimidaz $1 \mathrm{e}$ (BIA), ipher $\mathrm{yl}$ amine (DPA), 2-mercapto benzothiazole (MBTA) and N,N-dimethy anilin (DM- were placed separately in different isolated chamber in the specially desinne irtermos

After recording the initial weights of mild steel specimen ond M $\mathrm{er}$ To do, Japan AB 135-S/FACT, single pan analytical balance, (with a precis, of $0.01 \mathrm{~m}$, were kept in different isolated chamber (perfectly insulated from ea oth of air thcrmostat having fixed amount of VPCI at a constant temperature of 40 for 24 ho of exposure time. A uniform thin film of VPCI was adsorbed onto the me coupons after 2 hours of exposure.

Then these coupons were transferred to a digitally controlled humidity chamber maintained at $85.0 \%$ humidity at a constant tempera of $40{ }^{\circ} \mathrm{O}$ for 10 days. Blank coupons were also kept in the humidity chamber for the do ation in the same corrosive environment. After exposing the specimens days, me specimens were taken out from the humidity chamber and washed initially nde anning tap water. Loosely adhering corrosion products were removed with the he of ruber cork and the specimen was again washed thoroughly with triple di ntin water a d dried with hot air blower and then weighed again. Corrosion rate (CR) mils er year mpy) and percentage corrosion inhibition efficiency (PCIE) were calo ato ations (2) and (3) respectively [31].

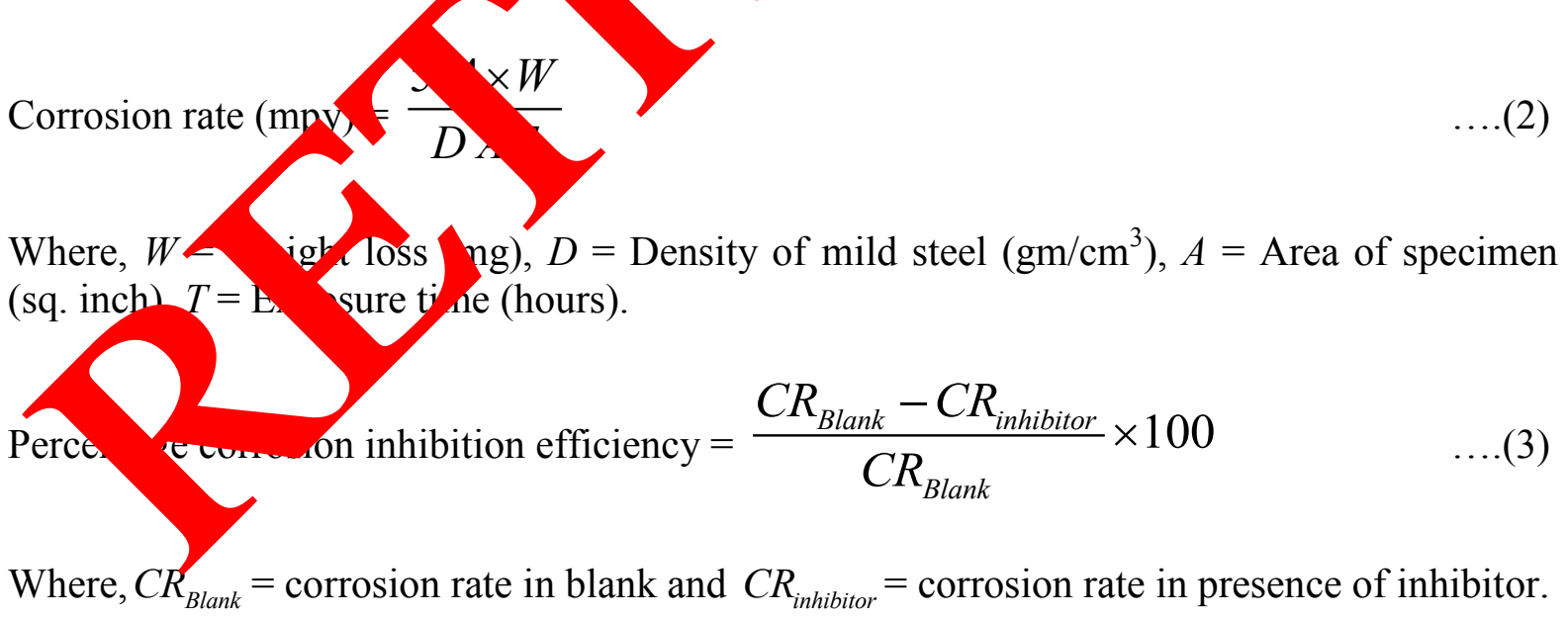

\section{3. Salt Spray Method}

After exposing the pre weighed mild steel coupons to VPCI in air thermostat for 24 hours, they were transferred to Salt Spray Chamber having 3.0\% sodium chloride solution maintained at constant temperature of $40{ }^{\circ} \mathrm{C}$ for duration of 10 days along with blank specimens. After exposing the specimens for 10 days, the specimens were taken out from the 
salt spray chamber and washed initially under the running tap water. Loosely adhering corrosion products were removed with the help of rubber cork and the specimen was again washed thoroughly with triple distilled water and dried with hot air blower and then weighed again. Corrosion rate (mpy) and PCIE were calculated using the equations (2) and (3), respectively.

\section{4. Eschke Test}

Eschke test was carried out on the pre weighed mechanically polished mild steel coupons as prescribed in the literature [32]. Kraft papers of suitable size were dir the VPCI for 30 second and then dried to adsorb uniform layer of the inhibitor on the $k$ papers. Then mild steel coupons were wrapped in VPCI impregnated Kraft pa rs and th transferred into the humidity chamber maintained at $85 \%$ relative humid $m$ man at a constant temperature of $40{ }^{\circ} \mathrm{C}$ for first 12 hours and $25^{\circ} \mathrm{C}$ for next 12 hour altern for 10 days. This temperature cycle was maintained in two sets be o corn tich and condensation of the vapors of VPCI on mild steel surface rearly. ter ex osing the specimens for 10 days, the specimens were taken out from the midity ch her and washed initially under the running tap water. Loosely adhering corre lon ducts we, removed with the help of rubber cork and the specimen was again wa thoro $\mathrm{ly}$ with triple distilled water and dried with hot air blower and then weigher again. Corrosio, ate (mpy) and PCIE were calculated using the equations (2) and (3), resp ctively.

\section{5. Sulphur dioxide Test}

$\mathrm{SO}_{2}$ test was carried out on the mild s dimension as in weight loss study. $\mathrm{SO}_{2}$ gas was produced by dissolving 04 , lium thiosulphate in $30 \mathrm{ml}$ aqueous solution of $1.0 \% \mathrm{NH}_{4} \mathrm{Cl}$ and $1.0 \% \mathrm{Na}_{2} \mathrm{SO}_{4}$ so aton ard $0.5 \mathrm{ml}$ of $1.0 \mathrm{~N} \mathrm{H}_{2} \mathrm{SO}_{4}$ was added to the round bottom single neck flos. finite a ount of VPCIs were taken in a Petridis and the flask, which is the source $\mathrm{O}_{2}, 2$ ong with etridis were placed in the isolated chambers of air thermostat. Initially on mild steel coupons were placed in air thermosta naintaine a constant temperature of $50{ }^{\circ} \mathrm{C}$ for duration of 10 days. After exposing ne cimens to cidic $\mathrm{SO}_{2}$ gas for 10 days, the specimens were taken out from the air the nosta dreated in the same manner as in Salt spray method and Eschke test. Co iosion rate ( $\mathrm{m}_{\mathrm{l}}$ and PCIE were calculated using the equations (2) and (3), respectively

\section{6. So ing E, tron dicroscopy (SEM) technique}

This echnique s employed for the surface study of mild steel coupons to know about natu of corrosion using SEM technique. The micrographs of the corroded specim were taken after exposure of 10 days. Micrograph of the blank mild steel coupons were also in for the comparative study of metal specimen.

\section{RESULTS AND DISCUSSION}

\section{1. Weight Loss Technique}

The values of weight loss (mg), corrosion rate (mpy) and PCIE for all the four VPCIs were shown in Table 3. The corrosion rate is found to be almost negligible in the coupons of mild steel treated with CA and BA. PCIE of all the four investigated VPCIs are shown in Fig. 
1. It is clear from Fig. 1 that all the four investigated VPCIs shows high PCIE i.e. $65-96 \%$. Out of the four investigated VPCIs, DMA exhibit highest PCIE i.e. 96.48 for the mild steel at $40.0{ }^{\circ} \mathrm{C}$ and DPA shows minimum i.e. 65.46. PCIE follows the order as DMA $>$ BIA $>$ MBTA $>$ DPA.

Table 3. Weight loss (mg), CR (mpy) and PCIE for all the four VPCIs for mild steel at $40{ }^{\circ} \mathrm{C}$ and $85.0 \%$ relative humidity after 10 days of exposure by weight loss method.

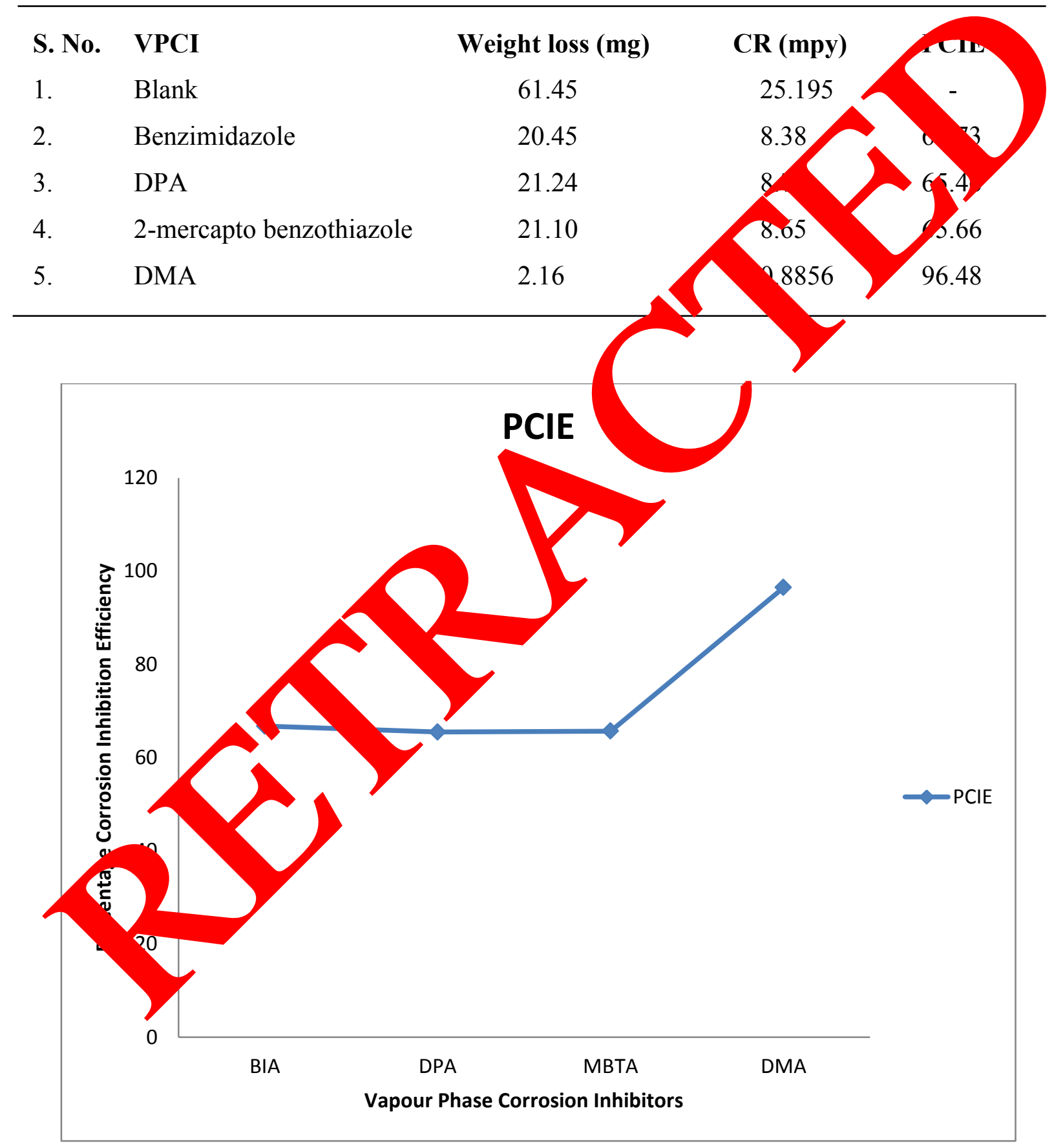

Figure 1. Percentage corrosion inhibition efficiency of all the four vapour phase corrosion inhibitors by weight loss method. 


\section{2. Salt Spray Method}

Weight loss (mg), corrosion rate (mpy) and PCIE of all the four investigated VPCIs at a temperature of $40.0^{\circ} \mathrm{C}$ by Salt Spray method were shown in Table 4. Fig. 2 shows percentage corrosion inhibition efficiency of all the four investigated VPCIs. As chloride ions are very aggressive from corrosion point of view, so a high corrosion rate was observed in salt spray method in comparison to weight loss method. All the four investigated VPCIs shows good corrosion inhibition efficiency i.e. 85.77 to $62.80 \%$ even in this aggressive environment and at a high temperature of $40.0^{\circ} \mathrm{C}$. The PCIE follows the order i.e. DMA $>$ DPA $>$ MBTA $>$ BIA.

Table 4. Weight loss (mg), CR (mpy) and PCIE of all the four VPCIs for mild steelaa ${ }^{\circ} \mathrm{C}$ and 85 $\%$ relative humidity after 10 days of exposure by Salt Spray Met' 1 .

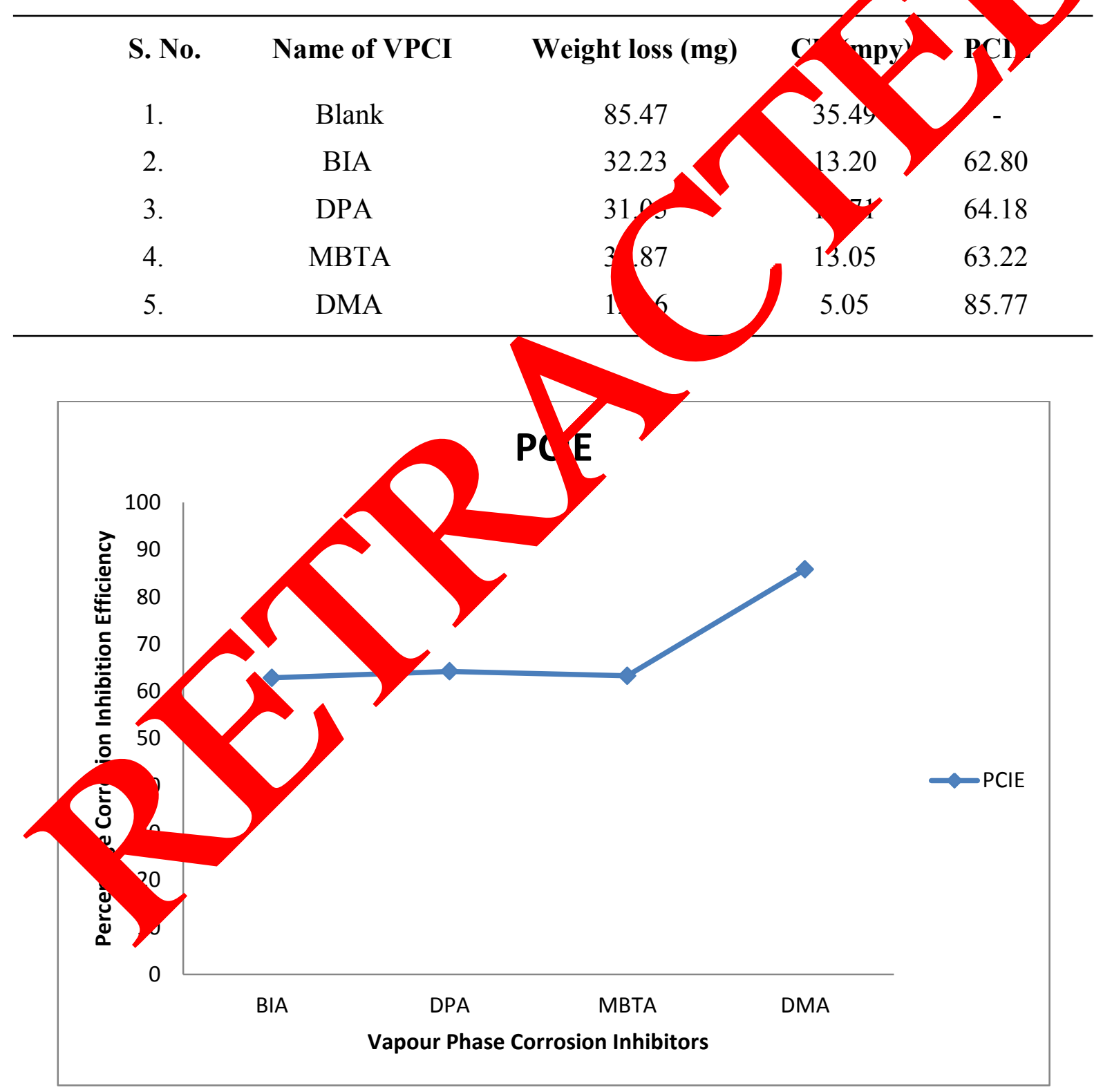

Figure 2. Percentage corrosion inhibition efficiency of all the four vapour phase corrosion inhibitors by Salt Spray method. 


\section{3. Eschke Test}

Weight loss (mg), corrosion rate (mpy) and PCIE of all the four VPCIs at $40.0^{\circ} \mathrm{C}$ after 10 days of exposure by Eschke test were shown in Table 5. Fig. 3 shows PCIE of all the four investigated vapour phase corrosion inhibitors. It is clear from the Fig. 3 that all the four investigated VPCIs shows very high PCIE i.e. more than $85.7 \%$. Out of these four, DMA shows 85.7 PCIE for mild steel. The PCIE follows the same order as in salt spray method i.e. DMA $>$ DPA $>$ MBTA $>$ BIA.

Table 5. Weight loss (mg), CR (mpy) and PCIE of all the four investigated VPCIs for $\mathrm{m}$ $40.0^{\circ} \mathrm{C}$ and $85.0 \%$ relative humidity after 10 days of exposure by Eschke T st.

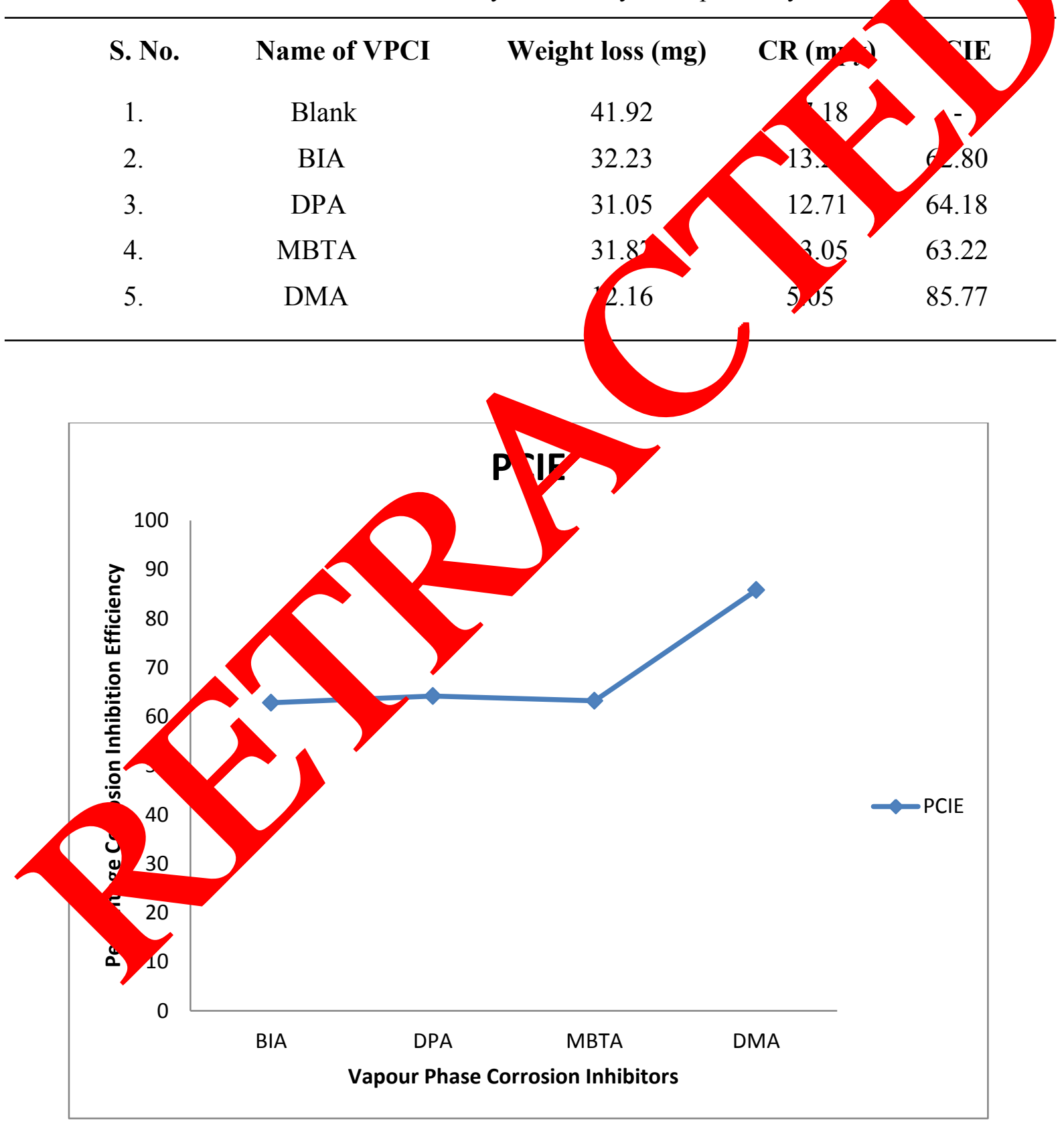

Figure 3. Percentage corrosion inhibition efficiency of all the four vapour phase corrosion inhibitors by Eschke method. 


\section{4. $\mathrm{SO}_{2}$ Test}

Weight loss (mg), corrosion rate (mpy) and PCIE of all the four VPCIs at $40.0^{\circ} \mathrm{C}$ after 10 days of exposure by sulphurdioxide test were shown in Table 6. Fig. 4 shows PCIE of all the four investigated vapour phase corrosion inhibitors. It is clear from the Fig. 4 that all the four investigated VPCIs shows very high PCIE i.e. more than $96.0 \%$. Out of these four, DMA shows 96.97 PCIE for mild steel. The PCIE follows the order i.e. DMA $>$ BIA $>$ DPA $>$ MBTA.

Table 6. Weight loss (mg), CR (mpy) and PCIE of all the four investigated VPCIs for mi $40.0{ }^{\circ} \mathrm{C}$ and $85.0 \%$ relative humidity after 10 days of exposure by $\mathrm{SO}_{2} \mathrm{Te}$

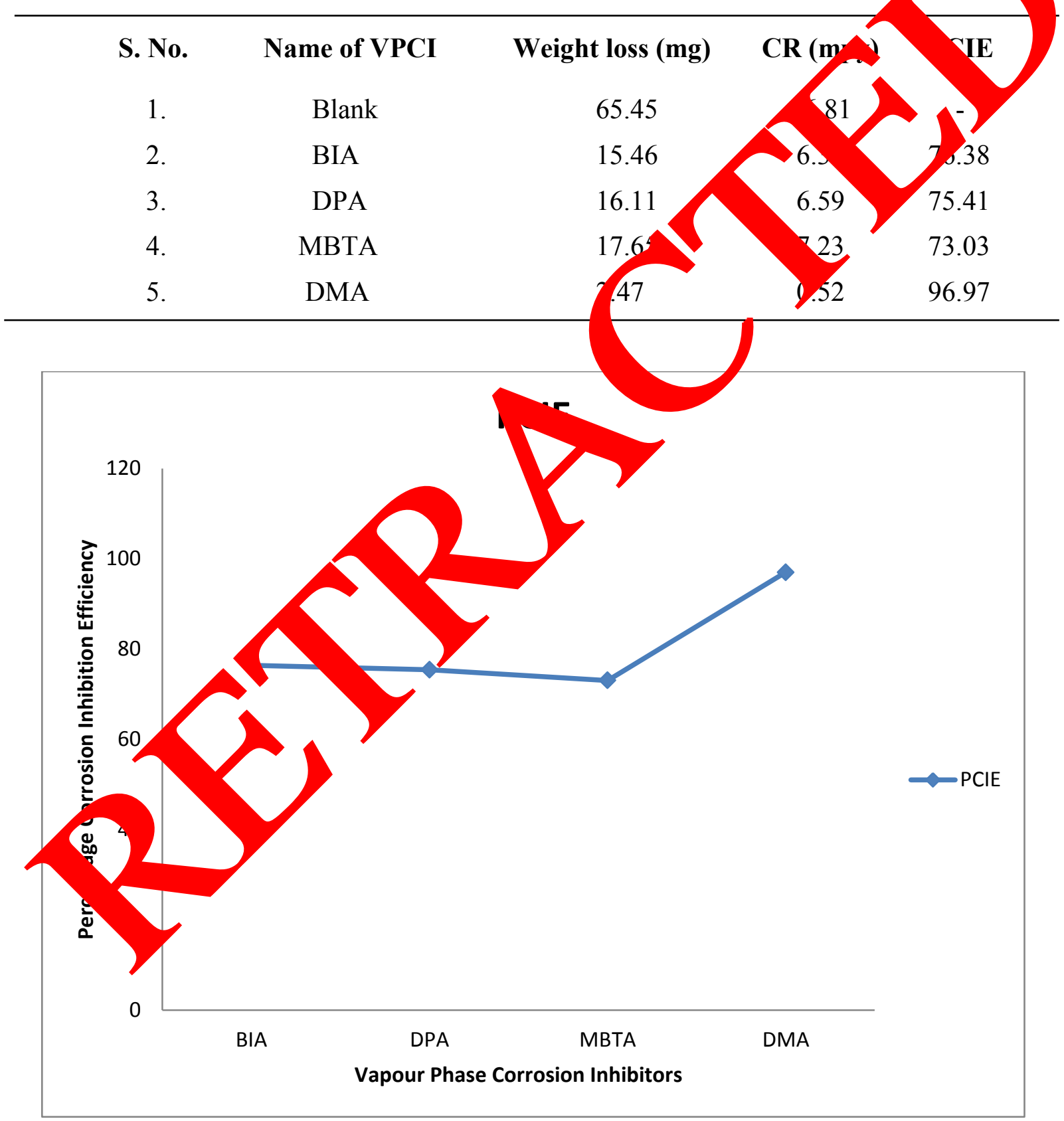

Figure 4. Percentage corrosion inhibition efficiency of all the four vapour phase corrosion inhibitors by $\mathrm{SO}_{2}$ Test. 


\section{5. SEM technique}

SEM images of mild steel coupons treated with different VPCIs by weight loss method after exposure of 10 days at $40.0^{\circ} \mathrm{C}$ were shown in Fig. 5. Pits are clearly visible in the images of blank coupons of mild steel showing pitting type of corrosion in absence of VPCI. The surface of mild steel coupon treated with DMA and BIA are smooth and clear which confirms the high PCIE shown by DMA and BIA against the atmospheric corrosion. There is uniform type of corrosion on mild steel coupons treated with MBTA.

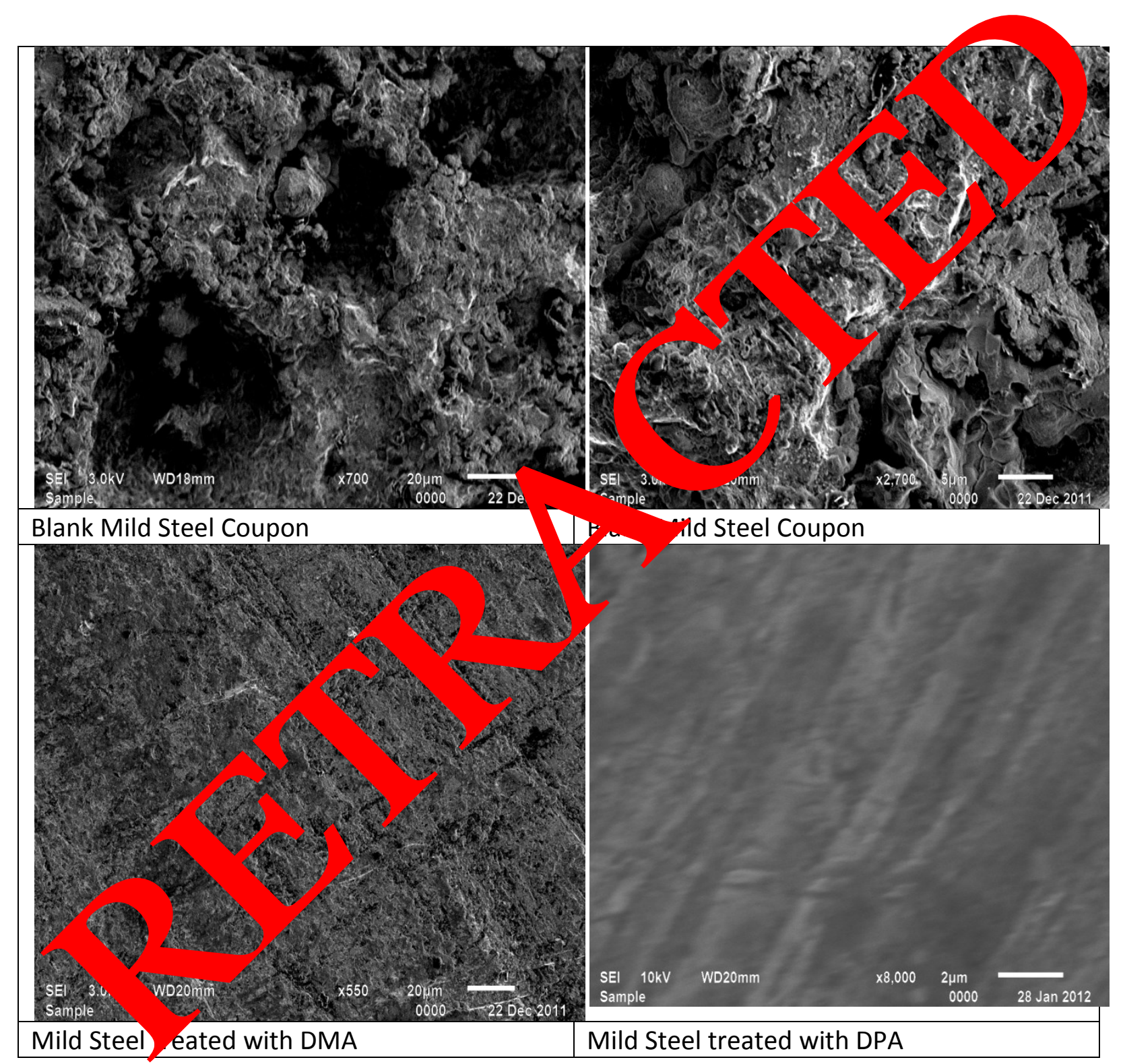

Figure 4. SEM images of mild steel coupons blank and treated with VPCIs. 


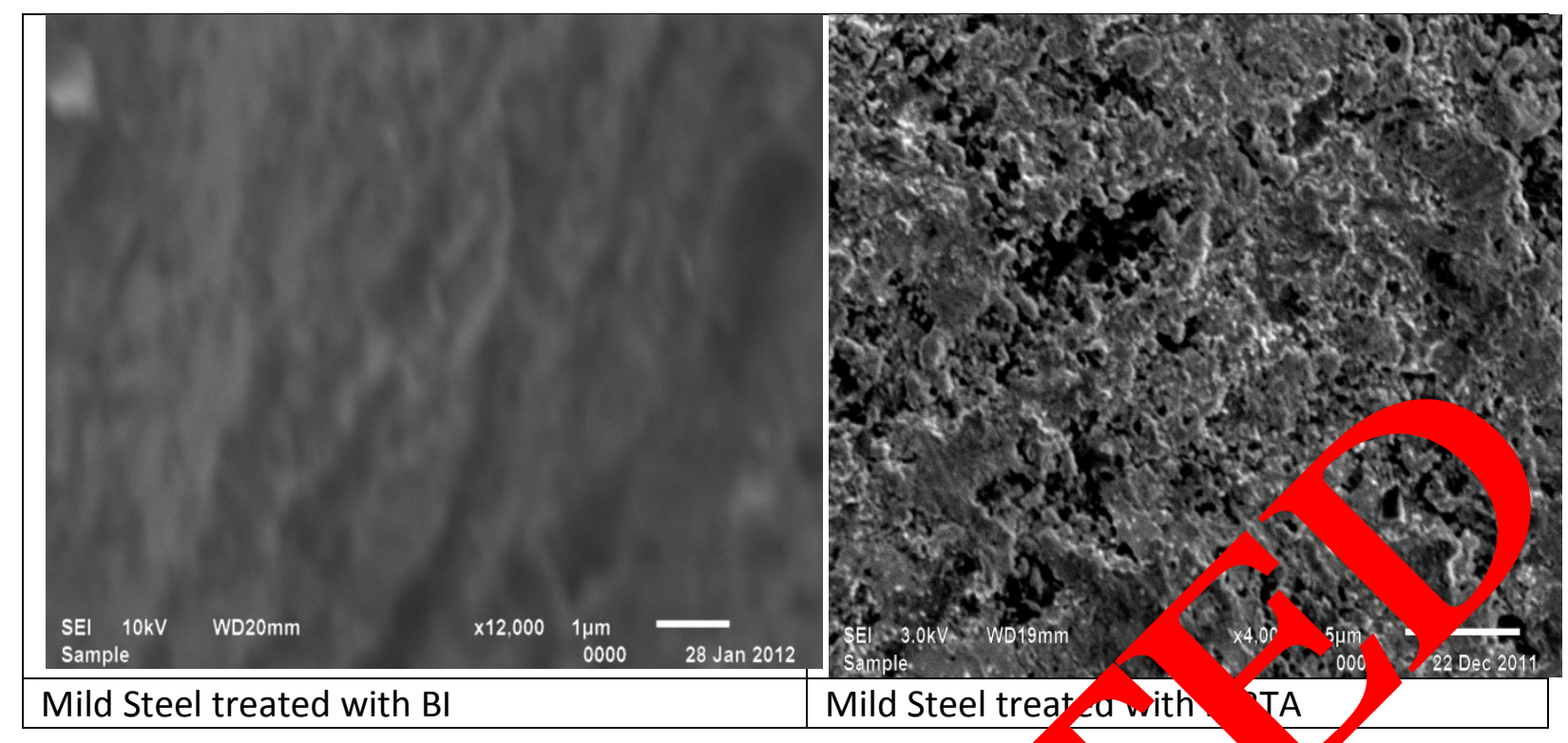

Figure 4 (continue). SEM images of mild steel coupons ank a treated wi.n VPCIs.

\section{MECHANISMS OF INHIBITION}

Inhibition of metallic corrosion in presence inveragated VPCIs involves the vaporization of the VPCIs in non dissociate lecular lom and followed by the adsorption of the vapors of VPCIs on the metal surface tue hetero atoms of inhibitors. VPCI functions $b$ ormins a bond on the metal surface and by forming a barrier layer to aggres ns. On ontact with the metal surface, the vapors of the VPCI are condensed and hydr lyzed by noisture to release protective ions. A VPCI must be capable of forming $[33,34]$. The VPCIs iny stigated resent study inhibited corrosion of metals in various ways:

- $\quad$ By saturat o the spa with their vapors and reducing the relative humidity below critical alue

- By lizin medum to a $\mathrm{pH}$ value at which the rate of corrosion become signific low.

- $\quad$ educin corrosion current density to a minimum value by rendering the metal sur ce hydro nobic which prevented the reaction of metal with environment.

1. presence of more number of lone pairs in the inhibitor enhances their inhibition efficiency $/$ presence of unsaturation and bulky alkyl groups near lone pair carrier atom retard their action due the resonance stabilization and steric hindrance respectively.

Very high percentage corrosion inhibition efficiency shown by DMA and DPA may be due to the following reasons:

1) By saturating the space with their vapors (due to high vapor pressure) and reducing the relative humidity below critical value.

2) Due to stronger adsorption to metal which forms uniform protective barrier film over the surface of metal. 
Low percentage corrosion inhibition efficiency shown by MBTA and BIA may be due to their low vapor pressure and presence of five membered ring destabilizes the molecule.

\section{CONCLUSION}

From the results of Weight Loss, Salt Spray, Eschke test and SEM techniques, the following conclusion can be drawn.

1. All the four investigated VPCIs show high percentage corrosion inhibition cy toward mild steel in different corrosive environment like high relative hur dity, 3.0 sodium chloride and high temperature i.e. $40.0{ }^{\circ} \mathrm{C}$.

2. Out of four investigated VPCIs, N-N-dimethyl aniline (DMA) (DPA) shows high corrosion inhibition efficiency in different corrosiy enviro nent.

3. VPCI saturate the space with their vapors and reducing humid cy below critical value and also alkalize the medium to a higher $\mathrm{pH}$ valy t which th te of corrosion become significantly low.

4. Percentage corrosion inhibition efficiency was fo be in order N-N-dimethyl aniline $>$ Diphenyl amine $>2$-Mercapto Benzothiaz e $>$ Benzimida ole in weight loss and salt spray corrosion experiments.

5. Results obtained from Weight Loss techniqu Fschke to st, Salt Spray method are in good agreement with each other inspite o different environment and are further supported by surface study carried out by SE in mique.

\section{Acknowledgment}

We are very thankful to support for this research wo

\section{References}

[1] Free M. Kla.g N., Ryu D. Y., Corrosion 60 (2004) 837-844.

[2] Rogmfeld I. 1982, Corrosion Inhibition, McGraw Hill Inc, New York.

[37 uzne or Y. L. 996). Organic inhibitors of Corrosion of metals, Plenum Press, New

[4] Jono A. (1996). Principles and preventions of corrosion, 2nd ed., Prentice Hall, Upper, addle River, N J.

[5] Bregmann J. L. (1963). Corrosion Inhibition, Macmillan Co., New York.

[6] Rosenfeld I. L. (1962). Proc. of the first International congress on metallic corrosion, 1962, Butterworth, London, p. 243.

[7] Stern A. C. (1968). Air Pollution, Academic Press, New York, p. 149.

[8] Subrumanian A., Natsen M., Murlitharan V. S., Balakrishan K., Vasudevan T., Corrosion 56 (2000) 144-155. 
[9] Sastri V. C. (1998). Corrosion Inhibitors Principles and Applications, John Wiley \& Sons, New York.

[10] Rajgopalan K. S., Ramaseshan G., J. Sci. Ind. Res. 19A (1960) 275-280.

[11] Subrumanian A., Gopalakrishan R., Bhupati C. S., Balakrishan K., Vasudevan T., Natesan M., Rengaswamy N. S., Bull. Electrochem. 14 (1998) 289-294.

[12] Saurbier K., Mandrof V., Hchultze G. W., Geke J., Penninger J., Robmeler H., Corros. Sci. 33 (1992) 1351-1359.

[13] Vuarinew E. K., Ngobeni P., Van der Klashorst G. H., Skinner W. De, Ernst Br. Corros. J. 29 (1994) 120-126.

[14] Sekine I., Sambongih M., Hogiuda H., Oshibe T., Yuasa M., Imoham T., s ata Y., Wake T., J. Electrochem. Soc. 139 (1992) 167.

[15] Muralitharan S., Pitchumani S., Ravicahneran S., and Iyur S. Soc. 142(1) (1995) 1478-1483.

[16] Zhang D. Q., Gao L. X., Mater. Perform 42 (2003) 40-

[17] Quraishi M. A., Jamal D., Ind. J. Chem. Tech. 11 (2 459-4,

[18] Quraishi M. A., Jamal D., Corrosion 58 (2002) 87-391.

[19] Tuken Yazici T., Erbil B., Progress in organic ating 50 (2 D04) 115.

[20] Starostina M., Smorodin A., Galor L., Material

[21] Rajendran S., Apparao B. V., Palanisw Horrosion and its control, Proc. of International Conference on Corrosio 1891 , ambai.

[22] Quraishi M. A., Bhardawaj nal D., d. J. Chem. Tech. 12 (2005) 93-97.

[23] Persiantsava V. P., Chen Re rew in Corrosion, Soviet Scientific Reviews of Mascow, OSSR 8(2) 197$)$ [24] Subrumanian A. san M., B. Sishan K., Vasudevan T., Bull. Electrochem,

[25] Kumar H. sami V., Yac V/(2013). Int. J. Engg. \& Innovative Tech. Accepted ISSN :22 $17-374$.

[26] Kumar h dav V. 3013) Am. J. of Materials Sci. \& Engg. 1(3) (2013) 34-39.

[27] H., Y. v.J., J. Corros. Sci. \& Engg. 16 (2013) Preprint 4.

[20, Uum r. Sain V., J. Corros. Sci. \& Engg. 14 (2012) Preprint 5.

[29] K ar H., Saini V., Res. J. of Chem. Sciences 2(2) (2012) 10-17.

[30] Dogrs S. K., Dogra S., Physical Chemistry through Problems, Wiley Eastern Limited, New Delhi, 1986, p. 231.

[31] Narayan R., An Introduction to Metallic Corrosion and its Prevention, $1^{\text {st }}$ ed, Oxford and IBH, 1983.

[32] Furman A., Chandler C., Test methods for Vapor Corrosion Inhibitors, Proc. $9^{\text {th }}$ Eur. Sym. Corros. Inhib., Ann. Univ. 11 (2000) 465. 
[33] Baligim S. A. (1996). Compets Rendus de 2eme Europeen Symposium Sur Les Inhibiteurs de Corrosion, Ann. Univ. 1966, Ferrara, N.S.

[34] Rosenfeld I. L., Persiantseva V. P., Polteva M. N., Inhibitors, National Association of Corrosion Engineers, 1972, 606-609.

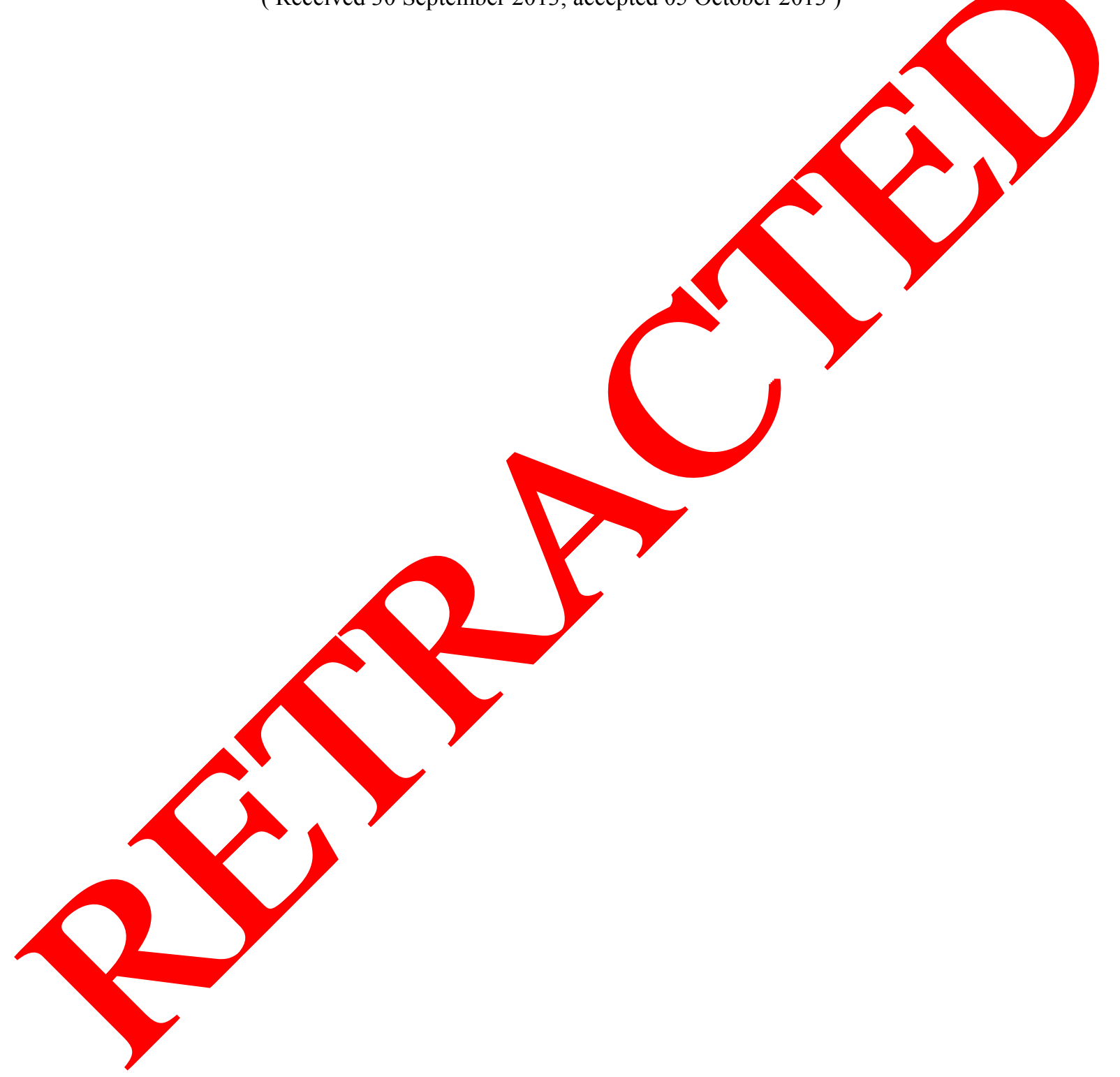

